*Pós-doutora em Direito pela Universidade Federal de Santa Catarina - UFSC. Doutora em Direito pela Universidade de Fortaleza - UNIFOR. Mestre em Direito pela Universidade Federal do Ceará - UFC. Graduada em Direito pela UFC e em Administração de Empresas pela UECE. Professora Adjunta do Curso de Direito da Universidade Estadual Vale do Acaraú - UVA. Coordenadora da Graduação e PósGraduação em Direito da Faculdade Luciano Feijão. Professora do Curso de Mestrado em Direito da UNICHRISTUS.E-mail: realbuquerque@yahoo.com

**Mestrando em Direito no Centro Universitário UNICHRISTUS.

Advogado. E-mail: souza_ mesquita@hotmail.com

\section{PrincíPIO da PRESERVAÇÃo da EMPRESA VERSUS PRINCÍPIO DA PROTEÇÃO AO TRABALHADOR: UM ENSAIO HERMENÊUTICO.}

\author{
PRINCIPLE OF COMPANY PRESERVATION VERSUS PRINCIPLE OF \\ WORKER PROTECTION: A HERMENEUTIC TEST
}

\section{Renata Albuquerque Lima* Sávio Luiz de Mesquita Souza**}

Como citar: LIMA, Renata Albuquerque; SOUZA, Sávio Luiz de Mesquita. Princípio da preservação da empresa versus princípio da proteção ao trabalhador: um ensaio hermenêutico. Revista do Direito Público, Londrina, v. 16, n. 2, p. 204-220, ago. 2021. DOI: 10.5433/24157-108104-1.2021v16n2p. 204. ISSN: 1980-511X

Resumo: O presente trabalho buscou como objetivo principal verificar os aspectos gerais e os efeitos da aplicação do princípio da preservação da empresa, bem como sua importância para o desenvolvimento econômico nacional, à luz do disposto no artigo 170 da CRFB/88, em harmonia com o princípio da proteção do trabalhador previsto no artigo $7^{\circ}$., caput da Carta Magna, ponderando seus limites e aplicação sob a ótica da hermenêutica constitucional, através da flexibilização de alguns direitos trabalhistas, a fim de enfrentar os obstáculos e crises impostos pela globalização no mundo do trabalho. A metodologia utilizada é a teórica, aliada ao raciocínio hipotético-indutivo, auxiliado por técnicas de pesquisa bibliográfica, mediante uma abordagem qualitativa do material estudado. A partir desse estudo, observouse que a flexibilização se apresentou como um fenômeno social capaz de ponderar a aplicação do ponto de vista hermenêutico, dos princípios da proteção frente ao princípio da preservação da empresa, na seara trabalhista, adequando as diversas mudanças de caráter social, econômico e tecnológico na órbita do binômio capital e trabalho.

Palavras-Chaves: Flexibilização; Princípio da proteção; Princípio da preservação da empresa.

Abstract: The present work sought as its main objective to verify the general aspects and the effects of the application of the principle of preservation of the company, as well as its importance for the national economic development, in the light of the provisions of article 170 of CRFB/88, in harmony with the principle of protection of the worker provided in article 7, main clause of the Magna Carta, pondering its limits and application 
from the perspective of constitutional hermeneutics, through the relaxation of some labor rights in order to face the obstacles and crises imposed by globalization in the world of work. The methodology used is theoretical, allied to hypothetical-inductive reasoning, aided by bibliographic research techniques, through a qualitative approach to the material studied. From this study, it was observed that flexibilization presented itself as a social phenomenon capable of pondering the application of the hermeneutic point of view, the principles of protection in the face of the principle of preservation of the company, in the labor field, adapting the various changes of a social, economic and technological nature in the orbit of the binomial capital and labor.

Keywords: Flexibilization; Protection Principle; Principle of preserving the company. 


\section{INTRODUÇÃO}

O processo de globalização tem caráter cosmopolita e é derivado das privatizações, e do caráter transnacional das relações privadas de trabalho sob o manto do neoliberalismo. No entanto, o amadurecimento social e a dignidade humana do trabalhador, diante desse processo que é uma realidade global, inevitável, e cada vez mais veloz, não pode sofrer retrocesso.

Com o argumento de mercado competitivo e desenvolvimento econômico, os defensores do neoliberalismo coadunam com a possibilidade de haver redução das garantias dos direitos fundamentais dos trabalhadores, devendo o Estado enxugá-las. Nasce a partir daí, uma crise filosófica que questiona a superioridade jurídica do trabalhador, através da intervenção do Estado social, colocando essa proteção, como alvo de grandes debates jurídicos, econômicos e sociais, aí levanta-se o questionamento para uma reflexão, de como deve ser essa atuação estatal, se por meio de um Estado ausente, interventor ou de natureza reguladora.

Dessa forma, o presente trabalho busca como objetivo principal verificar os aspectos gerais e os efeitos da aplicação ponderada do princípio da preservação da empresa, bem como sua importância para o desenvolvimento econômico nacional, à luz do disposto no artigo 170 da CRFB/88, em harmonia com o princípio da proteção do trabalhador, disposto no artigo $7^{\circ}$ caput, da Constituição da República Federativa do Brasil de 1988, ponderando seus limites e aplicação sob a ótica da hermenêutica constitucional, através da flexibilização de alguns direitos trabalhistas, a fim de enfrentar os obstáculos e crises impostos pela globalização ao mundo do trabalho.

Analisar-se-á em que hipóteses o princípio da proteção do trabalhador será submisso ao princípio da preservação da empresa, em prol de um desenvolvimento sustentável, onde os sujeitos sociais envolvidos na relação possam de forma consciente preservar seus interesses, desde que não sejam descumpridos preceitos constitucionais já sedimentos no ordenamento jurídico pátrio.

Tratar-se-á do fenômeno social da flexibilização como meio salutar de enfrentamento dessa dicotomia de aplicação e limites dos dois princípios aqui analisados, sob a ótica da hermenêutica constitucional, garantindo a manutenção dos direitos fundamentais dos trabalhadores e a preservação da empresa, a fim de que possa se ter um desenvolvimento responsável e preocupado com todas as questões sociais atinentes à sociedade.

A partir do que foi apresentado, pode-se concluir que o tema aqui discutido, apresenta grande relevância, não só acadêmica, como também para facilitar de forma ponderada a interpretação sob a ótica da hermenêutica constitucional, das questões e problemáticas econômicas, sociais e trabalhistas geradas pela globalização, diante da aplicação e limites dos princípios da proteção do trabalhador e da continuidade da empresa, no caso concreto, relacionados ao exercício da atividade econômica desenvolvida responsavelmente e sem abusos, pelas empresas no cenário de crise.

Inicialmente, no primeiro tópico, será feita uma abordagem geral sobre a globalização e os desafios enfrentados pelo direito do trabalho, tendo em vista as grandes mudanças ocorridas na seara trabalhista advindas dos avanços da tecnologia, dos mercados econômicos transnacionais, da fusão cultural com a quebra das barreiras geográficas e com as diversas variáveis sociais trazidas 
por essas mudanças globais.

Hoje o ordenamento trabalhista vive uma constante e incisiva fase de transição, onde constantemente, se põe em dúvida o protecionismo estatal nos diversos ramos do direito privado, mas, principalmente a intervenção do Estado nas relações trabalhistas.

No segundo tópico, analisar-se-á o conceito de flexibilização como fenômeno do milênio, principalmente na seara trabalhista, sua aplicação sob a ótica da hermenêutica constitucional nos casos concretos, seus limites impostos pela lei e pela jurisprudência.

A flexibilização deve ser compreendida e analisada como uma forma de se ponderar a aplicação de um sistema capaz de corresponder à nova conjuntura social no âmbito trabalhista, se ajustando às mudanças para suprir as necessidades do novo mercado econômico.

Portanto, para se chegar a essas conclusões outrora mencionadas, é importante ficar claro que a flexibilização como meio de ponderar a aplicação e limites entre os princípios aqui discutidos, não poderá contrariar em hipótese nenhuma, o ordenamento jurídico pátrio, muito menos, reduzir ou retirar direitos fundamentais dos trabalhadores.

Por fim, os dispositivos alterados pela flexibilização, devem ser analisados sob a ótica da hermenêutica constitucional, para que haja uma adaptação das relações trabalhistas diante das novas realidades trazidas pelo mercado globalizado e competitivo, protegendo a função social da empresa, sem se afastar da proteção constitucional do trabalhador.

No terceiro tópico, enfatizar-se-á a importância do Princípio da Continuidade da Empresa, como viga mestra da relação trabalhista, frente às modificações intensas e necessárias impostas pela globalização, para que o desenvolvimento econômico sustentável possa emergir na sociedade brasileira, diante de tantos mercados transnacionais e competitivos sob a ótica das questões sociais e da hermenêutica constitucional.

Concluir-se-á que se faz necessário que o direito do trabalho encontre um ponto de equilíbrio entre os interesses que são ao mesmo tempo conflitantes e harmônicos, do princípio de proteção ao trabalhador, contidos em diversos dispositivos de ordem pública e a necessidade contemporânea diante da busca do desenvolvimento econômico e da preservação da empresa.

Dentro desta conjuntura, o empregado aceita fazer um sacrifício, flexibilizando de forma responsável e não abusiva alguns direitos em prol da preservação da empresa e consequentemente do seu emprego. É o que acontece hodiernamente com a MP 936/20, que instituiu de forma emergencial a manutenção do emprego e da renda, reduzindo jornada de trabalho em prol da preservação do emprego, em tempos de pandemia de COVID-19. Neste diapasão, diante da conjuntura da globalização que atinge a toda sociedade mundial e a crise econômica da empresa, a flexibilização responsável e sem abuso, se mostra a melhor opção para dirimir o conflito.

Para a realização deste trabalho, a metodologia utilizada é a teórica, aliada ao raciocínio hipotético-indutivo auxiliado por técnicas de pesquisa bibliográfica, mediante uma abordagem qualitativa do material estudado.

1 GLOBALIZAÇÃO E OS DESAFIOS ENFRENTADOS PELO DIREITO DO TRABALHO 
O processo de globalização ${ }^{1}$ tem caráter cosmopolita e é derivado das privatizações, e do caráter transnacional das relações privadas de trabalho sob o manto do neoliberalismo ${ }^{2}$. No entanto, o amadurecimento social e a dignidade humana do trabalhador, diante desse processo que é uma realidade global, inevitável, e cada vez mais veloz, não pode sofrer retrocesso.

Em face da grande volatilidade do mercado, o Direito do Trabalho, passou e passa por uma profunda modificação, principalmente devido aos mercados cada vez mais competitivos, da quebra de barreiras geográficas, do lucro cada vez mais reduzido, da divisão internacional do próprio trabalho e da necessidade de maior produção.

Essas transformações advindas das modificações no trabalho e na economia, por conta da globalização, geram diversas consequências: crescimento do desemprego, desigualdades sociais, etc. Veja-se o que nos ensina Celso Renato de Albuquerque Mello:

Em outro sentido, a palavra globalização pode ser entendida como uma decorrência dos interesses planetários de poucos Estados, ou ainda, como uma decorrência do programa de meios de comunicação de massa. Pode-se dizer que é praticamente uma interpretação ecológica das relações internacionais. Se no mundo físico, a globalização pode ser um fato, já no mundo dos homens, isto é, político, é um ato que poderíamos dizer de livre-arbítrio. Só se globaliza o que se quer. E mais: a globalização é sempre realizada nos interesses de umas poucas grandes potências que, em seu nome, passam a agir em todo o planeta, a fim de salvaguardar os seus interesses. É óbvio que esta afirmação não pretende ser absoluta, vez que existem sempre as eternas exceções, como as crises econômicas em grandes potências (MELLO, 1996, p. 75).

Diante de todo esse processo de modificações, com o argumento de mercado competitivo e desenvolvimento econômico, os defensores do neoliberalismo coadunam com a possibilidade de haver redução das garantias dos direitos fundamentais dos trabalhadores. Nasce a partir daí, uma crise filosófica que questiona a superioridade jurídica do trabalhador, através da intervenção do Estado social, colocando essa proteção, como alvo de grandes debates jurídicos, econômicos e sociais.

Porém, num país de grandes desigualdades sociais, como o Brasil, as consequências da minimização do Estado são nefastas, pois nunca houve a efetivação de um Estado Social, ou seja, o Brasil nunca efetivou o bem-estar social dos trabalhadores. Dessa forma, analisando toda essa

1 Ressaltando as consequências negativas da globalização e do neoliberalismo, tem-se o trecho da obra de António José Avelãs Nunes (2003, p. 105), que defende: “a globalização é também um fenômeno de natureza cultural e ideológica, marcadamente imperialista na sua tentativa de submeter o mundo à ditadura do pensamento único. Esta tentativa é muito particularmente sentida (e não só de agora) no domínio das teorias e das políticas de desenvolvimento 'fabricadas' para exportar e aplicar, como produtos 'pronto a vestir', aos países ditos subdesenvolvidos."

2 Já para Robert Kuttner (2004, p. 211), o neoliberalismo político e a globalização econômica traz importantes contribuições à economia mundial, senão veja-se: "as maiores empresas do mundo estão envolvidas hoje num surto global sem precedentes de fusões, compras e concentração. Tornaram-se não só centros de poder econômico e financeiro concentrado; tornaram-se portadoras da ideologia de laissez-faire globalista preponderante. Enquanto seu poder econômico cresce, também cresce seu alcance político e intelectual, à custa de estados-nação que antigamente equilibravam seu poder econômico privado com objetivos públicos e políticas de estabilização nacional. O próprio sucesso econômico das empresas globais serve de prova que sua visão de mundo tem de estar correta: que o laissezfaire global é o melhor modo - de organizar a economia moderna." "iscep] 
situação estatal em que se encontra o Estado brasileiro, diante da globalização econômica, faz-se prudente a retomada de um Estado, não interventor, como presenciou-se no Estado de Bem-Estar Social, mas que seja considerado regulador, denominado de Estado de Responsabilidade Social (LIMA, 2018).

É notório, que nos últimos anos os direitos trabalhistas, em razão da crise econômica enfrentada no Brasil e pelo processo constante de globalização do mercado de trabalho, no quadro das transformações do capitalismo liberal, vêm sofrendo constantes ataques na sua efetivação como direito fundamental social.

Neste sentido, os empregadores reivindicam e impõe regimes e contratos de trabalho, cada vez mais flexíveis, bem como da grande massa de desempregados e subempregados, mão de obra barata e de trabalhadores sem colocação profissional no país. Nesse sentido, Robert Reich (2008) argumenta que a democracia empresarial é algo totalmente ilusório e que as empresas são efetivamente pilhas de contratos, senão veja-se:

Finalmente, chegarei a algumas conclusões que talvez sejam consideradas surpreendentes, entre elas: porque as iniciativas para melhorar a governança corporativa reduzem a probabilidade de que as empresas atuem com responsabilidade social; porque a promessa de democracia empresarial é ilusória; porque o imposto de renda incidente sobre as pessoas jurídicas deve ser abolido; porque as empresas não devem ter responsabilidade penal; e porque os acionistas devem ter meios para impedir que seu dinheiro seja usado pelas empresas para fins políticos, sem seu consentimento prévio. [...]. As empresas não são cidadãs. São pilhas de contratos. O objetivo das empresas é participar do jogo econômico com o máximo de agressividade e eficácia (REICH, 2008, p. 7, 12).

Portanto, a sociedade brasileira precisa tomar conhecimento dos seus direitos contidos na Constituição Federal de 1988, principalmente os de relevância social, como o direito do trabalho, para que possa impedir o retrocesso e a extinção de direitos conquistados a duras penas, pelas engrenagens sedutoras e implacáveis da globalização.

O ordenamento jurídico pátrio na seara trabalhista vive sofrendo constantes ataques pelos defensores do neoliberalismo, que baseados no discurso de mercado globalizado e competitivo, buscam a todos os momentos abalar os alicerces do protecionismo estatal ao trabalhador, em favor de seus interesses mercadológicos, defendendo uma relação equilibrada privada, entre trabalhador e a função social das empresas, sem a participação do Estado.

Outros reconhecem as mudanças sofridas pelos direitos fundamentais do trabalho, porém não defendem e nem concordam com a total ausência do Estado, pois têm consciência de que o Brasil ainda não efetivou o bem-estar social, pois ainda se possuem grandes desigualdades sociais, condições degradantes de trabalho, situações de trabalho escravo, ou análogo ao escravo e um grande desrespeito a legislação laboral.

Neste diapasão, diante da conjuntura da globalização que atinge a toda sociedade mundial e a crise econômica da empresa, a flexibilização responsável e sem abuso, se mostra a melhor 
opção para dirimir o conflito.

Porém, os estudiosos do Direito Laboral devem encontrar, por meio da ponderação, o ponto de equilíbrio para dirimir esta questão tão controversa e ao mesmo tempo harmônica, de um lado a sobrevivência da empresa, diante de um mercado cada vez mais transnacional e competitivo, e do outro a proteção dos direitos fundamentais do trabalhador, parte hipossuficiente da relação trabalhista.

Neste sentido, cumpre salientar diante da nova conjuntura apresentada pelos mercados globalizados, a importância em se ponderar, em se chegar ao meio termo, entre o direito a trabalhar, essencial para o empregado, e para isso a manutenção da empresa é primordial ${ }^{3}$, e o Direito do Trabalho em vigor, muitas vezes engessado e distante da realidade dos casos concretos nas relações trabalhistas.

O importante é garantir os direitos dos trabalhadores a renda e ao emprego, através do direito do trabalho, e para isso este precisa estar preparado para as mudanças trazidas pelos novos mercados, contudo, sem retroceder e nem extinguir direitos sociais, além de garantir a sobrevivência das empresas diante desta nova ordem mundial.

Portanto, a flexibilização responsável e sem abusos se mostra como mecanismo de efetivação dos direitos sociais dos trabalhadores, ao mesmo tempo, que se coloca como alternativa para dirimir situações complexas que surgem no cenário de crise econômica enfrentado pelas empresas, garantido a saúde e manutenção das mesmas.

Neste sentido, corrobora Vólia Bonfim Cassar (2018, p. 32), “poderá o Estado continuar regulamentando esta relação de trabalho e, excepcionalmente, permitir a redução de direitos trabalhistas sempre que no caso concreto estivar comprovada a precária situação econômica da empresa o que poderia acarretar sua extinção".

Portanto, é preciso encontrar o limite razoável, a ponderação para levar a melhor solução para sociedade, do conflito a ser dirimido da aplicação no caso concreto entre o princípio da proteção do trabalhador e o princípio da manutenção da empresa. Esse limite se chama flexibilização.

\section{FLEXIBILIZAÇÃO COMO FENÔMENO DO MILÊNIO}

As grandes mudanças ocorridas no cenário econômico mundial exigiram a necessidade de coadunar a legislação nacional aos anseios do mercado globalizado. Diante disso, surgiu a necessidade de adotar medidas que harmonizassem os interesses das empresas impactadas pela evolução do mercado transnacional e as necessidades sociais e econômicas dos trabalhadores garantidas pelos direitos sociais fundamentais.

Diante dessa necessidade de adaptação trazidas pela globalização fruto do neoliberalismo,

3 Sobre a necessidade de conservação da empresa, como fonte produtora de renda e emprego, Ecio Perin Júnior (2009, p. 5): "A empresa serve ao empresário e acionistas em geral como fonte de obtenção de lucros decorrentes do capital investido para sua constituição e desenvolvimento; aos credores, como garantia de venda de seus produtos, e por consequência, também à obtenção de lucros; à sociedade serve, uma vez que gera empregos, recolhe tributos e produz ou circula bens ou serviços, exercendo, dessa forma, função social indispensável, que proporciona, em sentido lato, a tutela da dignidade da pessoa humana". 
ensinam Mauricio Godinho Delgado e Gabriela Neves Delgado:

Os impactos da Revolução Industrial seguido das transformações trazidas pela globalização resultaram na flexibilização das leis e da atuação estatal nas questões relacionadas ao capital. Desta feita, a flexibilização é consequência da prática do neoliberalismo. Este último tem como premissa a mínima intervenção estatal nas políticas econômicas a fim de que haja rápida adequação do empresariado. Dadas as grandes mudanças pelas quais o mundo atravessou - mudanças tecnológicas, ampliação do mercado - com impactos profundos na economia, dificuldade de rápida adequação do capital e pelo fato da atividade industrial se destacar como "carro chefe" na economia, vários países europeus a exemplo da Inglaterra de Margareth Thatcher, efetuaram uma liberação extensa da economia de forma a promover uma maior competitividade econômica em seus países (desenvolvidos) e de orientar o crescimento dos países em desenvolvimento (DELGADO; DELGADO, 2017).

A flexibilização surge como medida para harmonizar esses interesses conflitantes entre empregado e empregador diante dessa evolução nos mercados globalizados, com a difícil tarefa de adaptar as novas relações trabalhistas com o ordenamento pátrio vigente, sem ocasionar retrocesso ou extinção aos hipossuficientes dessa relação.

Assim, a respeito da flexibilização, ensina Sérgio Pinto Martins:

O Direito do Trabalho vem sendo modificado constantemente e a flexibilização das condições trabalhistas emergiu para adaptar esse dinamismo à realidade laboral, ou seja, a flexibilização está em evolução junto aos sistemas de produtividade. Por isso, a flexibilização "é um conjunto de regras que tem por objetivo instituir mecanismos tendentes a compatibilizar as mudanças de ordem econômica, tecnológica ou social existentes na relação entre o capital e o trabalho" (MARTINS, 2012, p. 539).

Portanto, a flexibilização pressupõe a não extinção de direitos, o não retrocesso e a presença do Estado para garantir os direitos dos trabalhadores, ao mesmo tempo em que procura a todo custo proteger também a empresa, fonte do emprego, e que sem ele não haveria dignidade ao trabalhador, e muito menos garantia dos seus direitos. Assim corrobora Vólia Bonfim Cassar:

Flexibilizar pressupõe a manutenção da intervenção estatal nas relações trabalhistas estabelecendo as condições mínimas de trabalho, sem as quais não se pode conceber a vida do trabalhador com dignidade (mínimo existencial), mas autorizando, em determinados casos, exceções ou regras menos rígidas, de forma que possibilite a manutenção da empresa e dos empregos (CASSAR, 2018, p. $33)$.

Vale salientar, que a flexibilização responsável e sem abuso, é justificável quando se torna imprescindível para a harmonização através da interpretação do caso concreto, no que diz respeito à aplicação e limites dos direitos dos empregados e das empresas. Portanto, fora deste contexto de 
garantia e sobrevivência dos sujeitos da relação trabalhista não se justifica.

Veja-se o que ensina José Orlando Schäfer: “A flexibilização referente às transformações ocorridas no mundo do trabalho são justificáveis e devem ser consideradas. Por outro lado, a flexibilização que busca apenas a maximizações dos lucros, com o aniquilamento do sistema protetivo, deve ser combatida" (SCHÄFER, 2016, p. 35).

Portanto, como outrora mencionado, mister se faz para o Direito do Trabalho, através da hermenêutica constitucional, interpretar o caso concreto e identificar o equilíbrio entre os interesses que são ao mesmo tempo conflitantes e harmônicos, do princípio de proteção ao trabalhador, contidos em diversos dispositivos de ordem pública e a necessidade contemporânea diante da busca desenfreada do desenvolvimento econômico, da preservação da saúde da empresa. Sobre esses interesses conflitantes e harmônicos entre o principio da proteção e o da manutenção da empresa, Vólia Bonfim Cassar ensina:

Conflitantes porque o interesse do empresário não é o mesmo do trabalhador. $\mathrm{O}$ empregado quer ganhar mais e ter melhoria de sua condição de trabalho. O patrão quer pagar menos para ter maior lucro ou para manter o negócio saudável. Haverá harmonia de interesses quando o próprio empregado tiver consciência da situação precária de seu empregador, da dificuldade de nova colocação no mercado e da ameaça de desemprego, momento em que seus interesses convergirão com os do empregador, passando a perseguir juntos a recuperação da empresa (CASSAR, 2018, p. 33).

Dentro desta conjuntura, o empregado aceita fazer um sacrifício, flexibilizando de forma responsável e não abusiva, alguns de seus direitos em prol da preservação da empresa e consequentemente do seu emprego. É o que acontece hodiernamente com a MP 936/20, que instituiu de forma emergencial a manutenção do emprego e da renda, reduzindo jornada de trabalho em prol da preservação do emprego em tempos de pandemia de COVID-19.

Portanto, flexibilizar faz parte de um mecanismo mais abrangente e complexo, que é utilizado para adaptar o Direito do Trabalho, dotá-lo de condições para compatibilizar interesses, muitas vezes conflitantes, diante das diversas mudanças sofridas pela sociedade, como no caso concreto supramencionado do COVID-19. Assim ensina também Rosita Nassar:

A flexibilização das normas trabalhistas faz parte integrante de um processo maior de flexibilização do mercado de trabalho, consistente em um conjunto de medidas destinadas a dotar o direito do trabalho de novos mecanismos capazes de compatibilizá-lo com as mutações decorrentes de fatores de ordem econômica, tecnológica ou de natureza diversa. Isto significa que a flexibilização das normas trabalhistas não se exaure numa só medida, mas sim na totalidade do fenômeno da flexibilização, que é mais abrangente, compreendendo estratégias políticas, econômicas e sociais, e não apenas jurídicas (NASSAR, 1991, p. 76).

Não se deve confundir flexibilização com desregulamentação. A desregulamentação 
pressupõe ausência total do Estado, não há interferência do mesmo nas relações privadas, e consequentemente a revogação dos direitos do trabalhador impostos pela lei, ou seja, as questões litigiosas são dirimidas pelos próprios sujeitos da relação de trabalho. Por outro lado, a flexibilização é apenas a adaptação de regras protetoras do trabalho já vigentes no ordenamento jurídico, com a proteção do Estado, garantindo um mínimo fundamental ao trabalhador (CARTONI; LORENZETTI, 2008, p. 75).

Importante pontuar que na seara trabalhista, a flexibilização é possível e muitas vezes necessária para enfrentar as grandes crises vivenciadas pelas empresas que estão prestes a falir. A flexibilização responsável e sem abusos, em respeito ao princípio da preservação da empresa, de sua função social, a é a resposta mais harmônica para se evitar uma crise social mais grave, com a crescente taxa de desemprego, diminuição do mercado de trabalho e a consequente instalação do caos social, sempre lembrando da valorização dos postulados constitucionais da dignidade da pessoa humana e do princípio fundamental da proteção ao trabalhador.

Portanto, a flexibilização como meio de harmonizar os interesses entre a classe empresária e a profissional deve sempre respeitar o fundamento da dignidade da pessoa humana que representa o centro da gravidade da ordem jurídica que, por sua vez, legitima e condiciona todo o direito positivado (CARVALHO; LIMA, 2015). Neste mesmo sentido, a respeito do direito positivado alicerçado na dignidade da pessoa humana, ensina Vólia Bonfim Cassar:

Os temas relacionados com a flexibilização das relações trabalhistas e a sua limitação pelo princípio constitucional da proteção do trabalhador merecem maior reflexão em todos os sentidos, principalmente depois da aprovação da Reforma Trabalhista em 2017. A análise dos casos concretos e a formação da doutrina e jurisprudência consequente darão com o tempo melhor contorno a esta questão. O que não se deseja em uma sociedade civilizada é que haja maiores desrespeitos à dignidade humana e, particularmente, na sociedade brasileira, onde a desigualdade é flagrante, que não se viabilizem meios para conquista da igualdade substancial (CASSAR, 2018, p. 46).

Conclui-se, portanto, que a flexibilização como fenômeno do milênio, sem abusos, se faz necessária como medida de ponderação entre a preservação dos direitos fundamentais de proteção ao trabalhador frente à necessidade de preservação da empresa, trazendo sob a ótica da hermenêutica Constitucional, a eficácia econômica e consequentemente a garantia dos direitos sociais dos trabalhadores.

\section{COLISÃO ENTRE OS PRINCÍPIOS DA PROTEÇÃO E PRESERVAÇÃO DAEMPRESA, SOB A ÓTICA DA HERMENÊUTICA CONSTITUCIONAL.}

Diante do panorama delineado pelo novo mundo capitalista globalizado onde o desenvolvimento econômico tem como pressuposto um mercado cada vez mais competitivo na seara produtiva, o Direito do Trabalho se apresenta como paladino da justiça social, buscando 
através de seus princípios norteadores a forma para proteger o trabalhador, relativizando a autonomia privada, sem deixar para trás a preocupação com a saúde da empresa, geradora de emprego e consequentemente, aliada na efetivação dos direitos sociais fundamentais.

Portanto, o presente artigo não pretende esgotar o assunto, no que diz respeito aos princípios da proteção do trabalhador e o da preservação da empresa, mas tão somente mostrar a importância de ambos para o desenvolvimento econômico responsável, diante de um mercado cada vez mais competitivo proporcionando uma igualdade entre as partes.

Neste contexto, onde há colisão entre a aplicação dos princípios supramencionados, a hermenêutica constitucional tem um grande e importante papel, ou seja, dirimir a questão aplicando as regras de ponderação ao caso concreto, sempre aplicando aquele princípio que seja mais adequado, necessário, proporcional, menos invasivo em detrimento dos direitos fundamentais protegidos.

A hermenêutica constitucional como ciência que estuda a aplicação e sistematização do verdadeiro sentido das normas, cria uma base cognitiva, fundamental para que a opção por um dos princípios no caso concreto, seja uma escolha razoável, justa e quanto maior for a satisfação do seu emprego no resultado desejado, menor será a importância e aplicação do outro princípio.

A pedra fundamental do direito do trabalho, sendo seu principal objetivo, é resguardar o trabalhador de qualquer retrocesso, concedendo-lhe uma superioridade jurídica, uma vez que não existe uma igualdade material entre empregado e empregador na relação de trabalho, como acontece nas relações privadas no Direito Civil.

Portanto, o direito do trabalho tem como finalidade, através do princípio da proteção do trabalhador, mitigar a hipossuficiência do empregado, frente a superioridade econômica do empregador, trazendo nessa relação uma igualdade jurídica entre as partes. É claro que não se pode comparar a superioridade econômica do empregador, frente a situação econômica e de dependência do trabalhador, num país tão desigual como é o Brasil. Sobre esse desequilíbrio, preleciona Vólia Bonfim Cassar:

Em face deste desequilíbrio existente na relação travada entre empregado e empregador, por ser o trabalhador hipossuficiente (economicamente mais fraco) em relação ao empregador, consagrou-se o PRINCÍPIO DA PROTEÇÃO AO TRABALHADOR, para equilibrar esta relação desigual. Assim, o Direito do Trabalho tende a proteger os menos abastados, para evitar a sonegação dos direitos trabalhistas destes. Para compensar esta desproporcionalidade econômica desfavorável ao empregado, o Direito do Trabalho lhe destinou uma maior proteção jurídica. Assim, o procedimento lógico para corrigir as desigualdades é o de criar outras desigualdades (CASSAR, 2018, p. 171).

O princípio da proteção ao trabalhador aplicado nas relações entre empregado e empregador tem como alicerce fundamental a intervenção do Estado brasileiro, que legisla e impõe regras aos agentes sociais, e limita a vontade das partes, frente às desigualdades substanciais que caracteriza essa relação laboral. 
Plá Rodriguez afirma que historicamente o direito do trabalho surge das diferentes formas de exploração, inclusive, as mais abusivas e iníquas, geradas pela liberdade de se contratar entre pessoas de poder e capacidades econômicas desiguais (PLÁ RODRIGUEZ, 1978, p. 40).

Muita embora não haja consenso na doutrina laboral, se o princípio da proteção é gênero do qual decorrem todos os demais princípios especiais aplicáveis ao ramo trabalhista, sabese, no entanto, que a doutrina majoritária, defende que do próprio conceito do princípio tutelar mencionado acima se originam os subprincípios que o integram, são eles: princípio da norma mais favorável; princípio da condição mais benéfica; princípio in dubio pro operario.

Aqui, como anteriormente foi dito, não serão abordados todos os princípios do direito do trabalho, mas apenas os que geram a dicotomia hermenêutica do desenvolvimento econômico atual. Portanto, é do conhecimento de todos que o princípio da proteção ao trabalhador surge para mitigar desigualdade material gerada na relação trabalhista entre empregado e empregador, pois o capital econômico se concentra nas mãos de um único grupo, os empresários, o que no Brasil, país com grandes desigualdades sociais, gera uma necessidade de intervenção estatal para coibir a exploração do trabalhador.

Porém, ao mesmo tempo que é necessária essa intervenção, para garantir direitos do hipossuficiente, deve-se analisar, também a crise econômica enfrentada pelas empresas que estão prestes a falir, gerando com o seu fechamento, não a garantia de direitos, mas um desemprego em massa.

Realmente, é visível a crise enfrentada que enfraquece, e muito, o princípio da proteção ao trabalhador, o que pode ser facilmente constatado pela jurisprudência e súmulas mais recentes dos tribunais, que já não mais defendem ferozmente o trabalhador como outrora faziam, permitindo, em alguns casos, a redução de direitos ou a alteração in pejus.

Com a reforma trabalhista, (Lei 13.467/17), pode-se constatar que a proteção do trabalhador, outrora tão defendida pela sociedade como um todo, se encontra em crise e enfraquecida. Veja-se o que ensina Vólia Bonfim Cassar:

A alteração da CLT pela Reforma Trabalhista (Lei 13.467/17) e a ampliação das hipóteses de terceirização, acrescida pelas modificações que já vinha sofrendo a legislação trabalhista, comprovam o enfraquecimento do princípio da proteção ao trabalhador, pois cada vez mais se prestigia a autonomia da vontade do trabalhador no contrato de trabalho e em suas alterações, ignorando a sua vulnerabilidade (CASSAR, 2018, p. 173).

Portanto, a vulnerabilidade do trabalhador é uma realidade social incontestável, que deve ser combatida a todo custo pela sociedade em geral. No entanto, deve-se analisar o aspecto da vulnerabilidade por duas óticas, a ocasionada pela desigualdade material entre o empregado e empregador, e a ocasionada pelo fechamento e extinção da empresa, gerando um caos social sem precedentes e acometendo o empregado a uma vulnerabilidade ainda maior.

Logo após analisar-se-á o princípio da continuidade da empresa, ou da preservação da 
empresa, ou ainda da função social da empresa, que junto com o princípio da proteção geram uma dicotomia de desenvolvimento econômico responsável, que necessita de interpretação à luz da hermenêutica constitucional. Na obra Direito do Trabalho de acordo com a Reforma Trabalhista, Vólia Bonfim Cassar afirma:

Este princípio já era uma tendência mundial, mas só tomou fôlego em nosso país a partir da Carta de 1988, pelo art. 170 da CRFB. Isto porque no estudo da função social da propriedade percebeu-se que a empresa é uma das formas de exercício da propriedade. Daí por que a relação entre propriedade, empresa e direito do trabalho será abaixo estudada. Apesar de o tema ser badalado nos outros ramos do direito, não é ainda explorado pela doutrina trabalhista (CASSAR, 2018, p. 196).

A empresa, como um dos principais sujeitos responsáveis pelo desenvolvimento sustentável, desempenha um papel importantíssimo na sociedade, por ser propulsora da produção e por movimentar o mercado econômico, gerando renda e igualdade social. Grande parte da população depende diretamente dos postos de trabalho gerados pelas empresas, das receitas fiscais que são arrecadadas pelo Estado e posteriormente devolvido em forma de benefícios públicos, além dos produtos que produz e faz circular, proporcionando desenvolvimento. Neste sentido, preceitua Luiz Guerra:

Ainda que tardiamente, o ordenamento jurídico nacional reconheceu o óbvio reconheceu que a empresa é geradora de riquezas, de empregos, de rendas e de tributos. A função social da empresa é tão absoluta que a partir do momento em que o empreendedor inicia a atividade empresarial, embora a sua origem seja privatista, ganha ela feição publicista, passando o empresário individual ou o sócio majoritário ou acionista controlador a co-responsável pelo equilíbrio social e pelo desenvolvi- mento do país, porquanto na qualidade de agentes econômicos contribuem diretamente para o crescimento do Produto Interno Bruto (PIB) representado pela soma de todas as riquezas produzidas (GUERRA, 2011, p. 68).

No que diz respeito aos princípios da função social e da preservação da empresa, a Lei $n^{\circ}$. 11.101/2005 (Lei de falências e de recuperação judicial e extrajudicial das empresas) também faz menção em seu artigo $47^{4}$ a finalidade que o processo de recuperação judicial visa atingir, que é superação da situação de crise empresarial, focando a conservação da atividade empresarial. Além disso, Carpena afirma que o desvio do direito da função social da empresa acarreta abuso de direito, senão veja-se:

O desvio no exercício do direito da função social da empresa acarreta em uma das modalidades do abuso de direito. Assim, a empresa gozará de autonomia e liberdade enquanto respeitar os direitos dos trabalhadores, tanto aqueles previstos em lei quanto os relacionados ao trato, ao meio ambiente, à livre concorrência,

4 Art. 47. A recuperação judicial tem por objetivo viabilizar a superação da situação de crise econômica-financeira do devedor, a fim de permitir a manutenção da fonte produtora, do emprego dos trabalhadores e dos interesses dos credores, promovendo, assim, a preservação da empresa, sua função social e o estímulo à atividade econômica. 
ao pagamento de tributos, ao oferecimento de produtos, sem ferir o direito do consumidor etc. (CARPENA, 2001, p. 53).

Diante de todo o exposto, é forçoso concluir que o empregador que agir de má-fé, se aproveitando do instituto da flexibilização para aumentar seus lucros, em detrimento dos direitos fundamentais sociais dos empregados, abusa do direito consagrado nos dispositivos constitucionais, ferindo o princípio da dignidade do homem que trabalha, priorizando o capital ao trabalho humano decente.

Portanto, são notórios, dentro da relação de trabalho, os diversos conflitos de interesse que existem entre empregado e empregador. Diante da necessidade de ponderar esses conflitos, trazendo a pacificação social, mister se faz, pelas características de interesse público dos princípios da proteção do trabalhador e da preservação da empresa, analisar cada caso sob a ótica da hermenêutica constitucional, para saber qual o interesse que irá prevalecer.

Portanto, diante da importância dos dois princípios aqui sobejamente analisados, sob o manto da aplicação dos mesmos ao caso concreto, pode-se afirmar que o princípio da proteção do trabalhador só será submisso ao princípio da preservação da empresa quando a empresa estiver correndo risco iminente de falir, pois, deixando de existir, deixa também de oferecer postos de trabalho, receita ao Estado e desenvolvimento econômico, o que atinge de forma direta e prejudicial o próprio empregado. Apenas nessas hipóteses específicas haverá a aplicação do princípio da preservação da empresa em detrimento ao princípio da proteção ao trabalhador, pois, uma vez mantida a empresa, os empregos, a renda, a dignidade, a justiça social e todas as questões sociais atreladas a ela estarão também mantidos.

\section{CONSIDERAÇÕES FINAIS}

O Direito do Trabalho vem sofrendo diversas transmutações, sob o argumento da necessidade de se adaptar aos novos mercados transnacionais competitivos, na busca pelo desenvolvimento econômico, trazida pelo fenômeno da globalização. Diante dessa necessidade de adaptação, dois importantes princípios entraram em colisão, são eles: os Princípios da Proteção do Trabalhador, objetivo principal do direito do trabalho, e o Princípio da conservação da empresa, com sua função social preservando a manutenção do emprego.

Portanto, dentro da relação de trabalho, são notórios os diversos conflitos de interesse que existem entre empregado e empregador, reforçando a colisão desses princípios sobejamente mencionados. Diante da necessidade de se aplicar técnicas de ponderação para dirimir esses conflitos, trazendo a pacificação social, mister se faz, pelas características de interesse público dos princípios da proteção do trabalhador e da preservação da empresa, analisar cada caso sob a ótica da hermenêutica constitucional, para saber qual o interesse que irá prevalecerá em detrimento do outro, trazendo uma razoabilidade no resultado a ser alcançado.

Surgiu neste contexto de ponderação e razoabilidade a figura da flexibilização, representada 
pela necessidade de alteração de um conjunto de dispositivos no ordenamento jurídico, com o objetivo de adequar as mudanças impostas pelos novos mercados de caráter transnacionais, as relações de trabalho em virtude do fenômeno da globalização. A pedra fundamental do direito do trabalho, sendo seu principal objetivo, é resguardar o trabalhador de qualquer retrocesso, concedendo-lhe uma superioridade jurídica, uma vez que não existe uma igualdade material entre empregado e empregador na relação de trabalho, como acontece nas relações privadas no Direito Civil.

Portanto, esse objetivo se materializa, na concessão pelo Estado de uma superioridade jurídica ao trabalhador para tentar mitigar sua hipossuficiência, frente a superioridade econômica do empregador na relação laboral existente. Não menos importante, o princípio da preservação da empresa, ou da continuidade da empresa, ou ainda da função social da empresa se apresenta como um contraponto na relação trabalhista, diante do cenário de globalização e mercados cada vez mais competitivos, mostrando a necessidade diante desse cenário, de se buscar a sobrevivência da empresa, para consequentemente, manter a renda, o emprego, o desenvolvimento econômico sustentável, e o principal, os direitos sociais constitucionais do trabalhador.

Portanto, diante da importância dos dois princípios aqui sobejamente analisados, sob o manto da aplicação dos mesmos ao caso concreto, pode-se afirmar que existe imperiosa necessidade de interpretação hermenêutica para se ponderar a aplicação de cada princípio ao caso concreto, evitando a perda de direitos constitucionais do trabalhador, porém, garantindo a manutenção da função social da empresa que enfrenta diversas crises no cenário econômico hodierno.

Sob esta análise, diante da importância dos dois princípios aqui sobejamente analisados, sob o manto da aplicação dos mesmos ao caso concreto, pode-se afirmar que o Princípio da Proteção do Trabalhador só será submisso ao Princípio da Preservação da Empresa, quando a empresa estiver correndo risco iminente de falir, pois, deixando de existir, deixa também de oferecer postos de trabalho, receita ao Estado e desenvolvimento econômico, o que atinge de forma direta e prejudicial o próprio empregado.

Conclui-se, assim, que apenas nessas hipóteses específicas, sob à luz da hermenêutica constitucional, haverá a supremacia do princípio da preservação da empresa sobre o princípio da proteção, porquanto, uma vez mantida a empresa, os empregos, a renda, a dignidade, a justiça social e todas as questões sociais atreladas a ela estarão também mantidos.

\section{REFERÊNCIAS}

BRASIL. Constituição da República Federativa do Brasil de 1988. Disponível em: http:// www.planalto.gov.br/ccivil_03/constituicao/constituicao.htm. Acesso em: 21 dez. 2017.

BRASIL. Lei no. 11.101, de 9 de fevereiro de 2005. Regula a recuperação judicial, a extrajudicial e a falência do empresário e da sociedade empresária. Diário Oficial da União. Brasília, 10 fev.2005. Disponível em: http://www.planalto.gov.br/ccivil_03/_Ato2004-2006/2005/Lei/ L11101.htm. Acesso em: 12 abr. 2020. 
BRASIL. Lei no. 13.467, de 13 de julho de 2017. Altera a Consolidação das Leis do Trabalho (CLT) a fim de adequar a legislação às novas relações de trabalho. Diário Oficial da União. Brasília, 14 jul. 2017. Disponível em: http://www.planalto.gov.br/ccivil_03/_Ato2015-2018/2017/Lei/L13467.htm. Acesso em:12 abr. 2020.

BRASIL. Medida Provisória $n^{\circ}$. 936, de $1^{\circ}$. de abril de 2020. Institui o Programa Emergencial de Manutenção do Emprego e da Renda e dispõe sobre medidas trabalhistas complementares para enfrentamento do estado de calamidade pública. Diário Oficial da União, Brasília, 2 abr. 2020. Disponível em http://www.planalto.gov.br/ccivil_03/_Ato2019-2022/2020/Mpv/mpv936.htm. Acesso em: 12 abr. 2020.

CAPERNA, Heloísa. Abuso do direito nos contratos de consumo. Rio de Janeiro: Renovar, 2001.

CARTONI, Daniela Maria; LORENZETTI, Katiusca. A Flexibilização no Direito do Trabalho e a Globalização. Revista de Direito, Valinhos, v. 10, n. 13, p.73-86, 2008.

CARVALHO, Alexander Perazo Nunes de; LIMA, Renata Albuquerque. A eficácia Horizontal dos Direitos Humanos, Revista Opinião Jurídica, Fortaleza, ano 13, n. 17, p. 11-23, jan./ dez. 2015. Disponível em: https://www.academia.edu/37550359/CARVALHO_A._P._N. LIMA_R._A.._A_efic\%C3\%A1cia_horizontal_dos_direitos_fundamentais._Revista_ Opini\%C3\%A3o_Jur\%C3\%ADdica_Fortaleza_v._13_n._17_p._11-23_jan._dez._2015, Acesso em: abr. 2020.

CASSAR, Vólia Bomfim. Direito do trabalho: de acordo com a reforma trabalhista Lei 13.467/2017. 15. ed. rev., atual e ampl. Rio de Janeiro: Forense; São Paulo: Método, 2018.

DELGADO, Mauricio Godinho; DELGADO, Gabriela Neves. A reforma trabalhista no Brasil: com comentários à Lei n. 13.467/2017. São Paulo: LTr, 2017.

GUERRA, Luiz. Falências e recuperações de empresas: crise econômico- financeira: comentários à lei de recuperações e de falências. Brasília: Guerra, 2011. v. 1-4.

KUTTNER, Robert. O papel dos governos na economia global. In: HUTTON, Will; GIDDENS, Anthony. No limite da racionalidade. Rio de Janeiro: Record, 2004. p. 211-234.

LIMA, Renata Albuquerque. A atuação do Estado brasileiro e a crise empresarial na perspectiva da Lei de falências e de recuperação de empresas. 2. ed. Rio de Janeiro: Lumen Juris, 2018.

MARTINS, Sergio Pinto. Direito do trabalho. São Paulo: Atlas, 2012.

MELLO, C D. de Albuquerque. Aspectos jurídicos-políticos da globalização. Revista de Ciências Sociais, Rio de Janeiro, v. 2, p. 75, dez. 1996.

NASSAR, Rosita de Nazaré Sidrim. Flexibilização do direito do trabalho. São Paulo: LTr, 1991.

NUNES, António José Avelãs. Neoliberalismo e direitos humanos. Lisboa: Caminho nosso mundo, 2003.

PERIN JUNIOR, Ecio. Preservação da empresa na lei de falências. São Paulo: Saraiva, 2009. 
PLÁ RODRIGUEZ, Américo. Princípios de direito do trabalho. São Paulo: LTr, 1978.

REICH, Robert B. Supercapitalismo: como o capitalismo tem transformado os negócios, a democracia e o cotidiano. Rio de Janeiro: Campus-Elsevier, 2008.

SCHÄFER, José Orlando. Direito do trabalho e flexibilização. Porto Alegre: Sergio Antonio Fabis, 2016.

Como citar: LIMA, Renata Albuquerque; SOUZA, Sávio Luiz de Mesquita. Princípio da preservação da empresa versus princípio da proteção ao trabalhador: um ensaio hermenêutico. Revista do Direito Público, Londrina, v. 16, n. 2, p. 204-220, ago. 2021. DOI: 10.5433/24157-108104-1.2021v16n2p. 204. ISSN: 1980$511 \mathrm{X}$

Recebido em: 04/07/2020

Acesso em: 08/02/2021 